\title{
DETERMINAÇÃO DO TEOR DE ÉSTERES GRAXOS EM BIODIESEL METÍLICO DE SOJA POR CROMATOGRAFIA GASOSA UTILIZANDO OLEATO DE ETILA COMO PADRÃO INTERNO
}

\author{
Marcelo Volpatto Marques, Fabrício Fredo Naciuk, Ana Maria de Souza Mello, Nair Maria Seibel e Luiz Antonio \\ Mazzini Fontoura* \\ Departamento de Engenharia de Processos, Fundação de Ciência e Tecnologia, Campus de Cachoeirinha, Av. das Indústrias, 2270, \\ 94930-230 Cachoeirinha - RS, Brasil
}

Recebido em 5/8/09; aceito em 16/11/09; publicado na web em 24/3/10

\begin{abstract}
FATTY ESTER CONTENT DETERMINATION IN SOYBEAN METHYL BIODIESEL BY GAS CHROMATOGRAPHY USING ETHYL OLEATE AS INTERNAL STANDARD. A method for ester content determination in soybean methyl biodiesel was studied, using ethyl oleate as internal standard. A biodiesel sample was analyzed and had its purity estimated as $92.8 \%$. Method accuracy was evaluated by comparison with the result obtained via EN14103, with a relative difference of $0.1 \%$. Repetitivity and intermediate precision were estimated as 2 and $1.5 \%$, respectively.
\end{abstract}

Keywords: biodiesel; gas chromatography; ethyl oleate.

\section{INTRODUÇÃO}

Atualmente, a matriz energética mundial é baseada em fontes não renováveis, como gás natural, carvão mineral e, principalmente, petróleo. Após a crise energética na década de 70, em virtude de sucessivos aumentos no preço do petróleo e a iminência do esgotamento desta fonte de energia, aliado a uma consciência ambiental crescente, tornou-se emergencial o desenvolvimento de uma matriz energética sustentável, baseada em combustíveis alternativos renováveis. ${ }^{1-3}$

O biodiesel é um combustível renovável constituído por uma mistura de ésteres graxos obtida por reação de transesterificação entre um óleo vegetal ou gordura animal e um álcool na presença de um catalisador. ${ }^{4-7}$ A reação é mostrada no Esquema 1. Ao final de 2008, apesar da variedade de matérias-primas disponíveis, o biodiesel produzido no Brasil é obtido principalmente a partir de óleo de soja ${ }^{8}$ e metanol. ${ }^{9}$ Catalisadores homogêneos alcalinos, como hidróxido e metóxido de sódio, são os mais usados, especialmente este último.-6

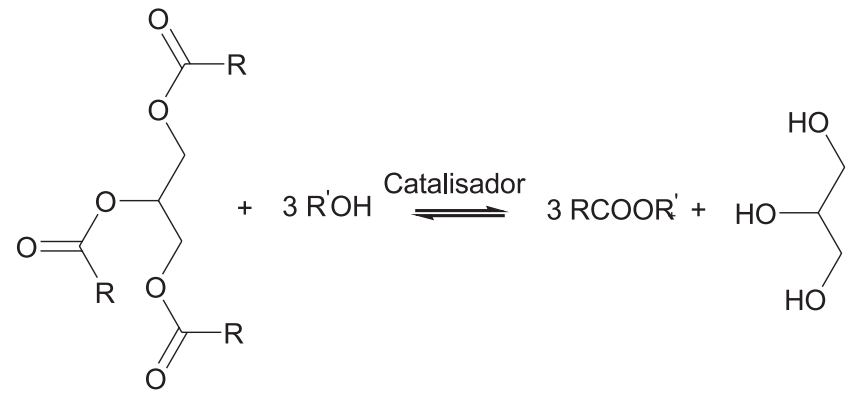

Esquema 1. Obtenção de biodiesel por reação de transesterificação de triacilglicerois

Diversas são as vantagens do uso do biodiesel como alternativa ao diesel fóssil: é renovável, polui menos, incentiva a economia e o desenvolvimento rural, apresenta maior número de cetano e ponto de fulgor, etc. ${ }^{4-6}$

No Brasil, o biodiesel foi introduzido na matriz energética pela Lei 11.097, de 13 de janeiro de 2005, determinando a sua obrigatoriedade

\footnotetext{
*e-mail: lmazzini@uol.com.br
}

de uso em mistura com o diesel fóssil na proporção de $2 \%$ a partir de 2008 e de $5 \%$ a partir de 2013. A mesma lei instituiu a Agência Nacional do Petróleo, Gás Natural e Biocombustíveis (ANP) que, entre outras atribuições, é responsável pela especificação do biodiesel. ${ }^{10}$

Um ano antes, a ainda chamada Agência Nacional do Petróleo (ANP) já havia especificado, através da Resolução 42, propriedades para o biodiesel comercializado no país bem como as técnicas analíticas para a sua caracterização. ${ }^{11}$ Entre as propriedades, essa Resolução determinava a quantificação do teor de ésteres graxos, isto é, a pureza do biodiesel, sem, entretanto, fixar valor mínimo. O método cromatográfico com padronização interna e calibração por um ponto, descrito na norma europeia EN14103, foi adotado como técnica quantitativa. ${ }^{12}$

Em março de 2008, a ANP publicou a Resolução n ${ }^{\circ} 7$ que estabelece $96,5 \%$ como a pureza mínima do biodiesel e aumenta a obrigatoriedade da adição de biodiesel no diesel para $3 \%$ a partir de julho daquele ano. ${ }^{13}$

Diversas técnicas têm sido empregadas na determinação do teor de ésteres em biodiesel, tanto no sentido de estimar a pureza do produto final quanto para acompanhamento da reação de transesterificação. Cromatografia gasosa com detector por ionização em chama (CG/ DIC), cromatografia gasosa com detector seletivo de massas (CG/ DSM), cromatografia líquida de alta eficiência (CLAE), cromatografia líquida com detector seletivo de massas (CL/DSM), ressonância magnética nuclear de hidrogênio e carbono $\left(\mathrm{RMN}-{ }^{1} \mathrm{H}\right.$ e $\left.{ }^{13} \mathrm{C}\right)$ e infravermelho próximo (IV) são alguns exemplos. ${ }^{5,14,15}$ A norma europeia EN14103 indica a cromatografia gasosa com detector por ionização em chama (CG/DIC) com padronização interna e quantificação com calibração por um ponto. Heptadecanoato de metila é o padrão interno. O método quantifica ésteres graxos metílicos com cadeias de 14 a 24 carbonos, saturados ou insaturados..$^{12}$

O heptadecanoato de metila é usado como padrão uma vez que se encontra ausente no biodiesel derivado da maior parte dos óleos. Além disso, atende aos principais requisitos de um padrão interno quando usado na determinação da pureza do biodiesel: é estável, tem estrutura química semelhante aos analitos e tempo de retenção compatível com estes últimos. A propósito, sua escolha vem do fato de ser um éster de um ácido graxo de cadeia com número ímpar de carbonos, o que é pouco comum em triglicerídeos de origem natural. É de uso extremamente abrangente, mas não é universal. De fato, o ácido heptadecanoico encontra-se livre ou ligado à glicerina no sebo bovino e em outras matérias-primas. Para matrizes como o biodiesel 
de sebo bovino, é importante o desenvolvimento de métodos alternativos. Uma possibilidade é o uso de um éster etílico como padrão interno no biodiesel metílico. Para tanto, é necessário que o cromatograma mostre a completa resolução entre os picos do padrão e dos ésteres metílicos que compõem o biodiesel. Quanto às características, o oleato de etila é comparável ao outro padrão.

Neste trabalho, apresentamos o uso de oleato de etila como padrão interno na determinação do teor de ésteres graxos em biodiesel metílico de óleo de soja. A exatidão do novo procedimento foi avaliada por comparação com o método europeu EN14103.

\section{PARTE EXPERIMENTAL}

\section{Preparação da amostra}

Cerca de $250 \mathrm{mg}$ de amostra de biodiesel metílico de soja foram pesados com exatidão em um frasco de $10 \mathrm{~mL}$ e dissolvidos com 5 $\mathrm{mL}$ de uma solução de $10 \mathrm{mg} \mathrm{mL}^{-1}$ de padrão interno em heptano. Foram usados como padrões internos heptadecanoato de metila 99,5\% (Fluka) e oleato de etila 98\% (Aldrich) e heptano PA (Vetec) como solvente. Foram preparadas 8 replicatas independentes da amostra com cada padrão interno.

\section{Análise cromatográfica}

As análises foram realizadas em um cromatógrafo a gás HP 6890 equipado com detector por ionização em chama e coluna HP-Innowax (comprimento: $30 \mathrm{~m}$; diâmetro interno: $530 \mu \mathrm{m}$; espessura do filme: 1 $\mu \mathrm{m})$. Volumes de $1 \mu \mathrm{L}$ de solução de amostra foram injetados manualmente em triplicata no modo splitless. As temperaturas do injetor e do forno foram ajustadas em $220^{\circ} \mathrm{C}$ e do detector em $250{ }^{\circ} \mathrm{C} . \mathrm{H}_{2}$ foi utilizado como gás de arraste a uma pressão constante de 3,93 psi.

A seletividade do método foi comprovada por comparação entre cromatogramas da amostra de biodiesel com e sem a adição do padrão interno. A precisão instrumental foi determinada através das medidas dos tempos de retenção e das áreas dos principais picos do cromatograma. Foram realizadas 8 injeções consecutivas de uma mesma solução. A precisão para cada parâmetro foi expressa através do desvio-padrão relativo (DPR). A exatidão foi avaliada por comparação com o método EN14103, o qual utiliza heptadecanoato de metila como padrão interno. A precisão intermediária foi determinada a partir de 3 resultados obtidos em dias diferentes por dois analistas distintos.

\section{RESULTADOS E DISCUSSÃO}

Nas condições experimentais utilizadas, o cromatograma é integrado no intervalo de 1,0 a 20,0 min, tempos de retenção correspondentes ao miristato de metila $(\mathrm{C} 14: 0)$ e ao nervonato de metila

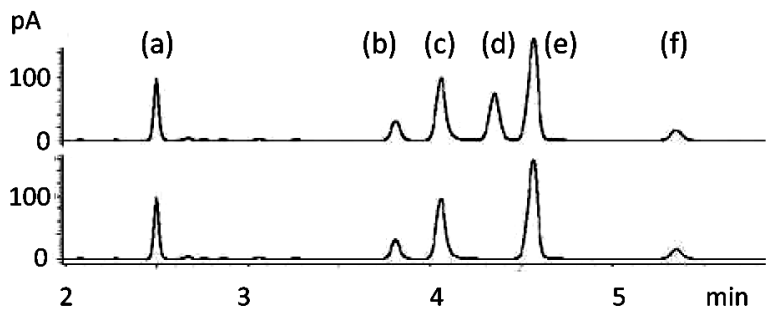

Figura 1. Cromatograma de biodiesel metílico de óleo de soja: ausência (abaixo) e presença de oleato de etila (acima): (a) palmitato de metila, (b) estearato de metila, (c) oleato de metila, (d) oleato de etila-padrão interno, (e) linoleato de metila e $(f)$ linolenato de metila
(C24:1), respectivamente. Este intervalo deve abranger os picos da maior parte dos ésteres derivados de fontes graxas.

A Figura 1 apresenta detalhe ampliado dos cromatogramas de uma amostra de biodiesel metílico de óleo de soja na presença (superior) e na ausência (inferior) do padrão interno, oleato de etila.

O intervalo de 2 a 6 min apresentado mostra apenas os tempos de retenção dos ésteres graxos que mais contribuem para a composição do biodiesel de soja. Padrões destes ésteres foram injetados e o tempo de retenção de cada um foi determinado. Assim, os picos encontrados foram atribuídos ao palmitato de metila (2,5 min), estearato de metila ( $3,8 \mathrm{~min})$, oleato de metila (4,1 $\mathrm{min})$, linoleato de metila (4,6 min) e linolenato de metila (5,3 min). O oleato de etila é eluído a 4,4 min. Comparando os cromatogramas, observa-se que o pico do padrão interno está ausente no cromatograma da amostra isenta do padrão (amostra branca).

Os desvios-padrão relativos (DPR) para oito medidas dos tempos de retenção $\left(t_{R}\right)$ e das áreas $(A)$ dos picos dos constituintes majoritários do biodiesel bem como do padrão interno foram usados como estimativas da precisão instrumental. Os resultados são apresentados na Tabela 1.

Tabela 1. Composição do biodiesel e precisão instrumental: tempos de retenção $\left(\mathrm{t}_{\mathrm{R}}\right)$ e áreas (A) médios e desvios-padrão relativos (DPR)

\begin{tabular}{lccccc}
\hline & \multicolumn{2}{c}{$\mathrm{t}_{\mathrm{R}}(\mathrm{min})$} & \multicolumn{2}{c}{ A (ua) } & \\
& Média & $\begin{array}{c}\mathrm{DPR} \\
(\%)\end{array}$ & Média & $\begin{array}{c}\text { DPR } \\
(\%)\end{array}$ & $\begin{array}{c}\text { Composição } \\
(\%)\end{array}$ \\
\hline palmitato de metila & 2,495 & 0,2 & 2457,4 & 5,0 & 14,3 \\
estearato de metila & 3,805 & 0,2 & 1248,0 & 3,1 & 7,3 \\
oleato de metila & 4,056 & 0,2 & 4436,1 & 3,1 & 25,8 \\
oleato de etila & 4,350 & 0,2 & 3523,7 & 3,1 & - \\
linoleato de metila & 4,565 & 0,2 & 7316,8 & 3,1 & 42,6 \\
linolenato de metila & 5,337 & 0,2 & 826,8 & 3,4 & 4,8 \\
\hline
\end{tabular}

Os valores de DPR para os tempos de retenção foram estimados em 0,2\%. O DPR para as áreas obtidas, por outro lado, variou de 3,1 a 5,0\%. São considerados adequados valores de até $2 \% .{ }^{16} \mathrm{Na}$ medida da área, a principal fonte de erro é o volume injetado, especialmente no caso da injeção manual. O erro da injeção, entretanto, perde importância quando a quantificação com calibração por padronização interna é usada.

Através das áreas relativas dos picos obtidos no cromatograma é possível obter a participação de cada éster graxo na composição do biodiesel. Os resultados são encontrados na Tabela 1 e correspondem a um perfil cromatográfico típico de um biodiesel derivado de óleo de soja. De fato, o biodiesel de óleo de soja é composto majoritariamente por ésteres de ácidos graxos insaturados, tais como oleato de metila e linoleato de metila. ${ }^{4,6,17}$

O pico mais próximo ao do padrão interno corresponde ao do linoleato de metila. A resolução entre ambos foi estimada em 1,3. Para fins quantitativos, uma resolução de 1,25 é considerada suficiente, ${ }^{18}$ especialmente em cromatogramas de misturas complexas, como é o caso do biodiesel.

A concentração de biodiesel $\left(C_{\text {biodiesel }}\right)$ é estimada através da Equação 1, na qual, $A_{T}$ é a área total integrada, $A_{P I}$ é a área do pico do padrão interno e $\mathrm{C}_{\mathrm{PI}}$, a concentração do padrão interno.

$C_{\text {biodiesel }}=\frac{\left(A_{T}-A_{P I}\right)}{A_{P I}} \times C_{P I}$

A amostra de biodiesel metílico de soja teve a sua pureza estimada usando-se o oleato de etila como padrão interno. Oito ensaios independentes foram realizados, fornecendo uma média igual a 92,8\%. Os resultados são apresentados na Tabela 2. 
Tabela 2. Pureza da amostra do biodiesel metílico de óleo de soja determinada por padronização interna com oleato de etila e heptadecanoato de metila

\begin{tabular}{|c|c|c|c|c|c|c|}
\hline \multirow{3}{*}{$\begin{array}{l}\text { Padrão } \\
\text { oleato de etila }\end{array}$} & \multicolumn{4}{|c|}{$\begin{array}{c}\text { Teor de ésteres } \\
(\%)\end{array}$} & \multirow[t]{2}{*}{$\begin{array}{c}\text { Média } \\
(\%)\end{array}$} & \multirow[t]{2}{*}{$\begin{array}{r}\text { DPR } \\
(\%) \\
\end{array}$} \\
\hline & 92,0 & 91,3 & 94,1 & 95,2 & & \\
\hline & 95,2 & 92,8 & 90,8 & 90,8 & 92,8 & 2,0 \\
\hline heptadecanoato & 92,8 & 92,2 & 92,9 & 93,2 & & \\
\hline de metila & 93,0 & 93,6 & 91,8 & 93,6 & 92,9 & 0,7 \\
\hline
\end{tabular}

A mesma amostra teve sua pureza também determinada por meio do método descrito na norma europeia EN14103, o qual utiliza heptadecanoato de metila como padrão interno. Usando igual número de ensaios, a pureza estimada pelo método oficial foi de $92,9 \%$. A exatidão do novo método foi avaliada comparando-se a média dos seus resultados com a obtida pelo método europeu. Os dois métodos forneceram resultados em excelente concordância, com uma diferença relativa de apenas $0,1 \%$.

Em ambos os casos, as repetitividades expressas como os desviospadrão relativos (DPR) foram estimadas em valores iguais ou inferiores a $2 \%$. Para métodos que quantificam pureza, repetitividades na faixa de 1 a $2 \%$ são consideradas adequadas. ${ }^{16}$

A precisão intermediária foi determinada a partir dos resultados de dois analistas distintos. Os resultados, obtidos por cada analista são apresentados na Tabela 3. A precisão intermediária, expressa como o desvio-padrão relativo (DPR), foi determinada como $1,5 \%$.

Tabela 3. Precisão intermediária - DPR (\%)

\begin{tabular}{lccc}
\hline \multicolumn{4}{c}{ Teor de ésteres (\%) } \\
\hline Analista & Experimento \\
& 1 & 2 & 3 \\
2 & 89,0 & 92,0 & 91,3 \\
& 89,0 & 91,7 & 91,0 \\
& & Média & 90,7 \\
& & DPR $(\%)$ & 1,5 \\
\hline
\end{tabular}

\section{CONCLUSÃO}

O uso de oleato de etila como padrão interno na determinação de pureza de biodiesel metílico de óleo de soja levou a resultado compatível com o fornecido pelo método EN14103. Nas condições experimentais, o pico do oleato de etila encontra-se suficientemente resolvido dos picos produzidos pelos componentes da mistura que forma o biodiesel, condição necessária para sua utilização como padrão interno.

\section{AGRADECIMENTOS}

À FINEP e à FAPERGS pelo apoio financeiro e ao CNPq pela bolsa concedida a M. V. Marques.

\section{REFERÊNCIAS}

1. Galembeck, F.; Barbosa, C. A. S.; Souza, R. A.; Quim. Nova 2009, 32, 571.

2. Goldemberg, J.; Quim. Nova 2009, 32, 582.

3. Vichi, F. M.; Mansur, M. T. C.; Quim. Nova 2009, 32, 757.

4. Marques, M. V.; Silva, C. F. G.; Naciuk, F. F.; Fontoura, L. A. M.; Analytica 2008, 33, 72 .

5. Meher, L. C.; Sagar, D. V.; Naik, S. N.; Renew. Sustain. Energy Rev. 2006, 10, 248.

6. Pinto, A. C.; Guarieiro, L. L.; Rezende, M. J. C.; Ribeiro, N. M.; Torres, E. A.; Lopes, W. A.; Pereira, P. A. P.; de Andrade, J. B.; J. Braz. Chem. Soc. 2005, 16, 1313 .

7. Schuchardt, U.; Sercheli, R.; Vargas, R. M.; J. Braz. Chem. Soc. 1998, 9, 199.

8. Duarte A.; biodieselbr 2009, 2, 19.

9. Freitas, R. C.; biodieselbr 2008, 1, 34.

10. http://nxt.anp.gov.br/NXT/gateway.dll/leg/leis/2005/lei\%2011.097\%20 -\%202005.xml?f=templates $\$ \mathrm{fn}=$ default.htm\&sync=1\&vid=anp:10.1048/ enu, acessada em Maio 2009.

11. http://nxt.anp.gov.br/NXT/gateway.dll/leg/resolucoes_anp/2004/ dezembro/ranp\%2042\%20-\%202004.xml?f=templates $\$ \mathrm{fn}=$ default. htm\&sync=1\&vid=anp:10.1048/enu, acessada em Maio 2009.

12. EN14103:2003; Fatty acid methyl esters (FAME) - Determination of ester and linolenic acid methyl esters contents, European Committee for Standardization: Brussels, 2003.

13. http://nxt.anp.gov.br/NXT/gateway.d1l/leg/resolucoes an p/ $2008 / \mathrm{mar} \% \mathrm{C} 3 \% \mathrm{~A} 7 \mathrm{o} / \mathrm{ranp} \% 207 \% 20-\% 202008$. $\mathrm{xml}$ ?f=templates $\$ \mathrm{fn}=$ document-frame. $h \mathrm{tm} \$ 3.0 \$ \mathrm{q}=\$ \mathrm{x}=\$ \mathrm{nc}=6637$, acessada em Maio 2009.

14. Monteiro, M. R.; Ambrozin, R. P.; Lião, L. M.; Ferreira, A. G.; Talanta 2008, 77, 593.

15. Knothe, G.; J. Am. Oil Chem. Soc. 2006, 83, 823.

16. Ribani, M.; Bottoli, C. B. G.; Collins, C.H.; Jardim, I. C. S. F.; Melo, L. F. C; Quim. Nova 2004, 27, 771.

17. Reda, S. Y.; Carneiro, P. I. B.; Analytica 2007, 27, 60.

18. Colins, C. H. Em Fundamentos de Cromatografia; Collins, C. H.; Braga, G. L.; Bonato, P. S., eds.; UNICAMP: Campinas, 2006, cap. 1. 